\title{
HABLA POPULAR Y RASGOS \\ DE PERSONALIDAD
}

Carlos F. Sabino Pauca Lazo'

\section{RESUMEN}

El presente trabajo está referido a un estudio cualitativo, basado en la utilización de las técnicas de observación y el análisis bibliográfico, sobre algunas de las características típicas del habla popular, en nuestro país, y su relación con las principales cualidades de la personalidad desde la perspectiva de la teoría científica. Mediante nuestra investigación hemos establecido categorías de términos del lenguaje común, cotidiano; para relacionarlos con las cualidades biológicas, psíquicas y sociales de la personalidad. Los resultados nos han servido para establecer que los conocimientos empíricos de los individuos de una sociedad que se expresan a través del lenguaje popular, altamente emotivo, permiten, en sus diversas variaciones, describir, explicar y pronosticar la conducta humana; constituyéndose en una importante herramienta espontánea para el proceso continuo de interacción y adaptación social.

Palabras clave: Habla popular, personalidad, psiquismo humano, conducta humana.

\section{I.- INTRODUCción}

El conocimiento popular, como resultado de la interacción social, es fuente inagotable para comprender las diversas formas del comportamiento humano. La sabiduría del común de la gente nos muestra cómo la experiencia va a la par o, a veces, se adelanta al conocimiento científico.

Las personas que configuran el tejido social de un pueblo, poseen diversos conocimientos sobre las características psicológicas de otras personas a las cuales las tipifican y nombran no con el lenguaje científico, sino con el habla.

'Psicólogo, Magister en Ciencias de la Educación.
"El Lenguaje, la palabra, es la unidad específica del contenido sensible y racional con que se comunican los hombres entre sí. El proceso de comunicación representa la expresión más compleja de las relaciones humanas. Es a través de la comunicación esencialmente que el hombre sintetiza, organiza y elabora de forma cada vez más intensa toda la experiencia y el conocimiento humano que le llega como individuo, a través de su lenguaje" Gonzales M. Psicología para educadores Pag. 241 -2001.

La palabra es la envoltura material del pensamiento y es el medio objetivo por el cual el lenguaje expresa una generalización en el sentido de, cuál es la forma de 
existencia de las personas.

El habla es un elemento vivo de la lengua y pese a los preceptos de la gramática, sigue evolucionando y produciendo nuevos términos incesantemente. El gramático hace su labor al decirnos cómo tenemos que ajustar nuestra lengua hablada $y$ escrita, pero el torrente impetuoso de la lengua hablada arrastra a aquella haciéndola evolucionar.

Un matiz de ese torrente impetuoso de la lengua hablada es el habla popular que comprende ciertas características particulares, expresadas en las variaciones de la emotividad y su simbología que son comprendidas mucho más fácilmente por la gente que las que ofrece la ciencia.

El lenguaje popular que adopta la gente en el hablar de todos los días,modifica las pautas reales de la lengua madre y se le utiliza para señalar las características psicológicas del individuo.

Ese tipo de lenguaje encierra un gran contenido simbólico y una enorme carga emocional que expresan valiosos significados. Generalmente es expresado con ingenuidad por el hombre común y presenta giros algo distorsionados respectos a las reglas aceptadas formalmente, pero que no se apartan de la función del lenguaje como es referirse a la actividad de las personas y su relación con los objetos.

En el lenguaje humano aparece casi siempre toda la expresión funcional de la personalidad: la unidad su actividad cognoscitiva-afectiva.

Los significados generalizados que se han fijado en el lenguaje y que reflejan la experiencia social, alcanzan en la personalidad un sentido individual que revela la actitud particular del que está hablando y no solamente sus conocimientos sino también sus vivencias afectivas.

La personalidad es un sistema social, psicológico y biológico que regula la función psíquica y su expresión a través de la conducta. Si el común de la gente no conoce la terminología científica para llamar por su nombre las características de la personalidad, entonces recurre al lenguaje popular; el mismo que se ha elaborado con denominaciones sui generis en base a la percepción de actos, conductas y actividades, tanto grupalmente como individuales. Así los rasgos de temperamento, carácter, capacidades, hábitos, costumbres, sentimientos, etc. son caracterizados de manera peculiar por el habla popular.

\section{OBJETIVOS}

Para nuestro trabajo nos hemos fijado los siguientes objetivos:

1.-Elaborar una nomenclatura de términos usados en habla popular.

2.-Establecer una relación entre los distintos términos del habla popular y las principales cualidades de la personalidad.

\section{II.- MATERIAL Y MÉTODOS}

Para investigar, primeramente, hemos utilizado técnicas documentales, las que nos ha permitido consultar fuentes contemporáneas sobre los diversos usos del habla popular en nuestro país. También 
hemos realizado un proceso de observación, sistematizada, para registrar las diferentes formas del habla con las que se expresa el pueblo en su vida cotidiana.

El volumen mayoritario de las palabras recopiladas tiene una acepción propia o local, que no es la misma que contiene la significación académica.

También hemos utilizado la base teórica acerca de la concepción científica de la personalidad.

\section{III.-RESULTADOS}

Para poder lograr los objetivos de nuestro trabajo, hemos establecido grupos de vocablos de uso popular, para compatibilizarlos con la teoría científica de la personalidad.

\section{GRUPO No. 01}

Aquí agrupamos términos referidos a personas con muy baja autoestima, poca valoración personal, inadecuado auto concepto, escasa idea de orgullo personal y tolerancia extrema a la hostilidad de los demás. Tenemos: El huevón, el boludo, el tetuto, el pelotudo, el cagado, el pichiruchi, el calentador, el punto, el zonzo, el pánfilo, gilazo, el cojudo, el baboso.

Las palabras muy despectivas como: cojudo, huevón, etc. significan una alusión al escroto masculino como símil de los senos de la mujer, es decir un menosprecio femenino atribuido a un varón. Además, el término cojudo, muy común en el habla popular, tiene un significado relacionado como cojo, que implica estar incompleto, mutilado.

\section{GRUPO No. 02}

Los términos de este grupo reflejan a personas básicamente serviles y extremadamente sumisas. Tenemos: El chupamedias, el lame platos, el carnero, el camotudo, el chupa medias, el chupa cirios, el franela, felpudini, el huele pedos , etc.

Los rasgos más típicos de este grupo son el sobón y chupamedias. Son de carácter débil, dependiente y sugestionable. Pese a recibir trato despectivo y hasta agresivo, manifiestan conductas casi masoquistas. Están prestos a hacer cualquier acción por recibir un gesto que alimente su débil ego. Se observa este tipo de conductas en los ámbitos laborales, entre algunos subalternos y sus jefes; también en las relaciones de pareja donde uno de ellos se ha sometido al otro al cual no logra complacer nunca. Rasgos a veces patológicos.

\section{GRUPO No. 03}

En este grupo están aquellas personas excesivamente amables, tolerantes, generosas, etc. para con los demás. Son llamados: El pan de dios, el bueno, el botarate, el mano abierta, el paño de lagrimas, el doctor corazón, el una madre.

Estas personas demuestran un desprendimiento desmedido para con otros, están dispuestas siempre a ayudar, hasta se colocan en situaciones problemáticas por esa idea fija de ser asistencialistas, caritativos, filántropos, etc. Puede ser un desorden de los sentimientos, que lejos de ser una cualidad resulta un defecto. 


\section{GRUPO No. 04}

Aquí percibimos rasgos formados por hábito o costumbre, en los que algunas personas no han aprendido ni desarrollado capacidades para satisfacer por si mismos sus necesidades, ser parte activa y útil de los grupos a los cuales pertenecen. Tenemos: El comechao, el mantenido, el vividor, el zángano, el sanguijuela, el parásito, etc.

El sujeto busca satisfacer sus necesidades sin esfuerzo, requieren para ello de la solvencia de otras personas como parientes, amigos, pareja, etc. Su conducta refleja una actitud negativa hacia la productividad. En algunos casos está afectada la salud mental por no tener metas en la vida y valerse por sí mismos. Por ello son tratados con hostilidad. marginación y menosprecio.

\section{GRUPO No. 05}

Aquí señalamos a personas de reacciones lentas, pasivas, inertes, etc. que necesitan de algún estimulo o motivación externa, constante, para poder realizar sus actividades. Su comportamiento causa incomodidad, fastidio y decepción por su escaso dinamismo e iniciativa. Tenemos: El dejado, el lento, el lerdo, el flojo, el tortuga, el pachochas, el después, el mañana.

Son gente de temperamento flemático, en ellos prima la lentitud por una baja reactividad del sistema nervioso. Son proclives a la procastinación y la tendencia a la pereza, desgano e inercia psicológica.

\section{GRUPO No. 06}

Aquí se señala a personas extrovertidas, rápidas. Han desarrollado, empíricamente, habilidades persuasivas y de sugestión. Usan de la simpatía, los halagos y la lisonja con el propósito de lograr algún beneficio. Tenemos: El trepador, el zalamero, el pendejo, el meloso, el vivo, el encandilador.

Son sujetos que se valen de muchas artimañas para poder sacar ventaja de ellas, especialmente de la adulación. En la vida familiar lo aplican los esposos y hasta los hijos cuando desean conseguir un beneficio.

\section{GRUPO No. 07}

En este grupo están quienes son muy tímidos, huidizos, inhibidos y rígidos que se sienten incómodos frente a una situación nueva o desconocida y no se interesan por participar socialmente. Tenemos: El pavo, el corto, el monse, el mongo, el hongo, el achicao, el quedado, el calzonudo, el caído del catre, el achanchao.

Se trata de personas que prefieren la vida alejada de los demás, expresan miedos, temores por la cercanía social. Son fríos, distantes y apáticos. Introvertidos en exceso.

\section{GRUPO No. 08}

Los términos del habla popular señalan a personas que establecen distancias en formas selectivas, rígidas e inflexibles. Tenemos: El bacán, el sobrado, el creído, el pituquito, el más mas, el bacanazo, el men.

Personas sobrevaloradas que recurren a la egolatría, la soberbia y la arrogancia como herramientas de relación social. Desconocen la modestia y la sencillez. Tienen una falsa percepción sobre sí mismos. Esa altivez, generalmente, es una máscara que utilizan como mecanismo de 
defensa ante su fragilidad, inseguridad y falta de confianza.

\section{GRUPO No.09}

Términos que se refieren a personas que tienen como característica principal la obstinación o terquedad. Siempre buscan salirse con la suya o imponer sus criterios e ideas. Carecen, temperamentalmente, de flexibilidad para percibir y comprender otros criterios. En este grupo tenemos:El contreras, el terco, el Jalisco, el mula, el alegoso. Son oposicionistas ante el sentir de los demás, un rasgo típicamente infantil. Explosivos y dominantes, en unos casos son de temperamento desequilibrado y en otros, débil.

\section{GRUPO No. 10}

Aquí, se incluye a quienes hacen uso del histrionismo para dejar una percepción agradable en los demás. Su conducta siempre está orientada a llamar la atención, tanto en su forma de comunicarse como en el vestir y actuar. Aquí tenemos: El teatrero, el huachafo, el firulete, el peliculero, el faite, el blablabla, el hablantín, el papirriqui.

Denota a personas de carácter débil, superficiales e inmaduros emocionalmente. Sus sentimientos son muy lábiles y volubles, cambiantes. No asumen sus obligaciones con responsabilidad.

\section{GRUPO 12}

Conforman este grupo quienes usan la fuerza para sacar provecho y ventaja de los demás. Tenemos:El prepotente, el sangrón el tiburón, el chupasangre, el cabrón, el negrero, el sableador, el vividor, el buscón, el loba.
Personas con dificultades en el equilibrio emocional. Tienen casi nula la práctica de habilidades sociales, especialmente la empatía. Son abusivas, pues tienen la idea que la fuerza es el mejor medio para imponerse ante los demás. Tratan a las personas como sus subordinados y cuando encuentran, en ese trato, a una persona con rasgos masoquistas forman una simbiosis de características patológicas.

\section{GRUPO 13}

Términos que señalan a personas con ausencia significativa de valores sociales, morales y éticos. Usan la mentira, el engaño y la traición para sus fines. En este grupo tenemos: El tramposo, el cuentero, el atorrante, el vendido, el mierda, el torcido, el palero, el lanza, el sabido, el revesero, el cuchillo, el bocón, el soplón, el perro muertero.

Estas personas usan la mentira para lograr el engaño, inventan historias para hacer caer a los incautos. Otra característica típica es la persona de doble moral. Son pasivos agresivos. Puede estar en cualquier lado en pro de sus intereses particulares. Es el hipócrita que utiliza una aparente amistad para emboscar o agredir.

\section{GRUPO No. 14}

Palabras referidas a personas que se tienen un afán desintegrador. Son inoportunos, impulsivos, faltos de sentido común y de prudencia. Con ello generan incomodidad y malestar en las relaciones interpersonales y de grupos. Tenemos: El carbonero, el cachasiento, el saca pica, el metete, el espeso, el kuaquer, el saco de plomo, el metiche, el acusete, el partidor, el aguafiestas. 
Estas personas con sus actitudes de desunión desestabilizan grupos. Por su comportamiento impulsivo y poco reflexivo no logran adaptarse armónicamente entre los demás. Causan rechazo y antipatía.

\section{GRUPO 15}

Los que agreden constantemente a los demás mostrando actitudes violentas, impulsivos, descontrolados y muestran un afán constante de dominio. Tenemos: EI gran puta, el maloso, el chucha, el jodido, el desagraciado, el jijuna, el fregado, el san putas, el mala sangre, el roncoson, el batidor, el maldito, el verraco, el azabache.

Palabras como el chucha y el sanputas, tienen un alto grado de contenido sexual destructivo. La agresividad y violencia son el significado de los términos señalados.

\section{GRUPO 16}

Términos que expresan recelo, desconfianza y sensibilidad significativa. Tenemos: El quisquilloso, el picón, el arisco,el delicado, el llorón, el lagrimita, la dolorosa, el plañidero, el bilioso, el fosforito.

Estas personas son muy sensibles a cualquier opinión o crítica. Su temperamento débil los condiciona a estas reacciones que son impredecibles, a veces se presentan muy dóciles y en otras muy tercos y difíciles. Siempre hay una tendencia a la hiper sensibilidad y labilidad emocional.

\section{GRUPO 17}

Personas que acortan distancias, rompen formalismos; algunos son insensibles a la crítica. Suelen hacer cosas indebidas frente a los demás, no conocen de frenos o reguladores éticos de su conducta.
Tenemos: El confianzudo, el tuteador, el entrador, el fresco, el lechuga, el sinvergüenza, el conchán.

Estas personas no tienen reparos en la distancia social, transgreden los espacios y la distancias de los demás.

\section{GRUPO 18}

Palabras que agrupan a personas que gustan y buscan compañía. Son extrovertidos, tienen buen sentido del humor, mantienen una actitud motivadora. Típico temperamento Sanguíneo. Buena capacidad de adaptación, flexibilidad y orientación hacia los demás; sin caer en el servilismo o la dependencia. Tenemos: El amiguero, el socio, el patero, el desenvuelto, el de Triana, el suelto, el chochera.

Confían en sí mismos, son capaces de acercarse amablemente. Suelen inspirar admiración y confianza. Denotan muy buenas actitudes en relación a los rasgos del carácter por los cuales e hacen práctica de la empatía y adecuada valoración del entorno social.

\section{GRUPO 19}

Personas cumplidoras, perfeccionistas y muy productivas. Inspiran confianza y respeto. El ladrillo, el derecho, el cumplido, el aplicado, el chamba, el formal.

Personas con muy buenos rasgos del carácter relacionados con el trabajo, con valores significativos respecto a la responsabilidad y el cumplimiento del deber.

\section{GRUPO 20}

Los luchadores activos que saben enfrentarse con valor a los retos. Tenemos 
El enrazado, el machazo, el de agallas, el de pelo en pecho, el de temple, el de cojones.

Personas que se caracterizan por que enfrentan con bastante fuerza, ahínco y entereza las tareas y dificultades que tienen que afrontar.

\section{IV.- DIscusión}

Existe una especie de clasificación basada en el habla popular, que, definitivamente, es menos rigurosa y sistemática que la de la ciencia, pero es válida en cuanto a su conocimiento y su utilidad práctica.

Es preciso destacar que en los vocablos estudiados, se observa en ellos una fuerte carga emocional; por eso son considerados como "malas palabras" (malas emociones) sobre todo aquellas que abiertamente expresan agresividad o sexualidad.

Si relacionamos estos argumentos con las funciones psicológicas del lenguaje estudiados por diversos lingüistas, encontramos que la caracterología científica esencialmente conceptual, cumple una función esclarecedora, en cambio la caracterología popular, además de cumplir con esta función, cumple a plenitud las funciones expresivo catártica, donde la emoción y no el intelecto juega un papel importante.

Las expresiones populares ya manifiestas en este trabajo pueden parecer inapropiadas, pero creemos que como estudiosos de la psiquis humana y su expresión concreta, la conducta, podemos discutirlas con una perspectiva científica.

Entre todos los tipos psicológicos estudiados, hay tres: el chucha, el pendejo y el cojudo, que por su alto contenido emocional y su fuerza expresiva, resumen a todos los otros y en los que se aprecia una gradiente de la actividad que va desde la dinámica hasta la pasividad, de lo hostil a lo erótico y de lo masculino a lo femenino.

La gran cantidad de palabras para referirse tanto al homosexual masculino como a las personas pasivas y a la enorme carga de desprecio implícita en estas expresiones nos muestran el lado ideal de la virilidad y de agresividad, que no es otra cosa que el machismo exacerbado.

\section{CONCLUSIONES}

- El lenguaje popular elabora una caracterología empírica de la personalidad que no tiene rigidez científica, pero se condice con la teoría Psicológica y tiene un gran valor para describir, explicar y predecir la conducta.

- El habla popular es una muestra del desarrollo constante del lenguaje, cuyos giros hacen evolucionar al idioma.

- El lenguaje popular tiene un alto contenido emocionalyen muchas de sus expresiones contiene mensajes destructivos.

\section{REFERENCIAS BIBLIOGRÁFICAS}

BUHLER, Karl Teoría del LenguajeRevista de occidente Madrid- 1950.

DSTEFANO:A.O. EI Psiquismo Humano-Edit. Axioma-Bs. As. 1994.

DUBINI N. P. Genética, Conducta y Personalidad - Edit. Cartago Bs. As. 1985.

GRADO, L. Fernando Diccionario de Peruanismos. IMPEGUSA-Lima-1998. 
LEONTIEV, A. N. Psicología Social Edit. Ciencias del hombre Bs. As. 1978.

Psicología- Edit. Grijalbo. México. 1980.

LÓPEZ IBOR, Juan J. El libro de la vida sexual. Edit. DANAE- Barcelona-1981.

LURIA, A. El hombre nuevo - Edit. Martínez Roca - Barcelona-1987

MERANI. A. Psicobiología- EditGrijalbo- México-1980.

PERLMAN, D - COZBY, P.C. Psicología Social - Edit. Interamericana
México1986.

SHERKOVIN, Yu. A. Fundamentos de Psicología Social y de la PropagandaInstituto de Ciencias Sociales. Moscú1985.

VOGOTSKI, Liev S. :Pensamiento y Lenguaje Psicología Pedagógica- Edit. AIQUE-Bs. As. 2001.

\section{PAgINAS WeB}

www. queondas. com/aqui.../index. php?opti on noticia-habla-culta-marthahildebrandt-diccionariodelajergaperuana. blogspot.com/www. elbuscapersonas. com.
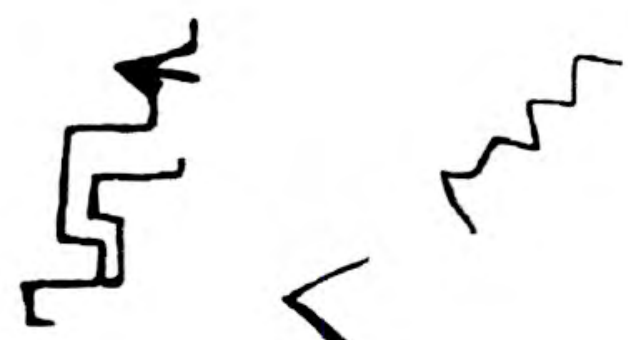